\title{
The role of sensitization to dental materials for the manifestation of idiopathic urticania and angioedema
}

Maria Dencheva ${ }^{1}$, Maya Ljapina ${ }^{3}$, Dimitar lovchev, Elena Petkova ${ }^{2}$, Denislava Nedeva², Anna Valerieva ${ }^{2}$, Stella Hristova ${ }^{4}$, Vassil Dimitrov ${ }^{2}$

1. Medical University-Sofia, FDM, Department of oral and image diagnostics;

2. Medical University-Sofia, UMBAL Alexandrovska, Clinical center of allergology;

3. Medical University-Sofia, Medical Faculty, Department of Hygiene, medical ecology and nutrition;

4. Private dental practice - Sofia.

\section{Abstract}

Idiopathic urticaria and angioedema are states of unclear etiology, abruptness and unpredictability. Approximately $40-50 \%$ of patients with chronic spontaneous urticaria have angioedema, as well and about $10 \%$ of them have isolated angioedema. Modern dental treatment is associated with the usage of different dental materials. Their influence is diverse and often associated with negative consequences such as the occurrence of mucosal lesions, burning mouth syndrome and even urticaria and angioedema. 


\section{Aim of the study:}

To study the sensitization to dental materials in patients with idiopathic form of urticaria and angioedema.

\section{Material and Methods:}

110 patients were involved in the current study. The patients were divided into 3 groups: Patients with Angioedema $(n=11)$, Patients with Urticaria and ANE $(n=39)$, Control group $(n=60)$. Patch test was done with dental materials of both types - from whole products and from components of dental products allergenic series of company Chemotechnique Diagnostics IQ Chambers $\AA$, Vellinge, Sweden and series developed by the NCCPD - Sofia. All participants were undergone prick test for latex sensitization.

\section{Results:}

A statistically significant difference in sensitization to dental materials was found among patients with idiopathic urticaria and angioedema $(p<0.001)$ compared to healthy control group.

\section{Conclusions:}

Sensitization to dental medicines and materials can be proved by means of patchtest with standardized allergens from individual components of the final product or standardized allergens from whole products. We recommend carrying out the complex testing for detailed study of allergy background in patients with idiopathic urticaria and angioedema.

\section{Key words: urticaria, angioedema, dental materials, dental treatment;}

\section{Introduction}

Idiopathic urticaria and angioedema are states of unclear etiology, abruptness and unpredictability. Approximately $40-50 \%$ of patients with chronic spontaneous urticaria have angioedema, as well and about $10 \%$ of them have isolated angioedema [1,2]. Modern dental treatment is associated with the usage of different dental materials. Their influence is mixed and often associated with negative consequences such as the occurrence of mucosal lesions, burning mouth syndrome and even urticaria and angioedema. The allergic reaction to dental materials occurs most frequently as IV-th type of reaction from Coombs \& Gell's classification [3,4]. The immunological basis of patchtest is type IV (cell-mediated or delayed) hypersensitivity reaction. In this case, specifically sensitized T-lymphocytes have a secondary contact with the antigen that is usually in hapten form conjugated to a protein and expressed on the surface of antigenpresenting cell (APC). Langerhans cells (LC) are the main APC in the skin located basically in the 
epidermis, where they form a net. They are dendritic cells of bone marrow origin having on their cell surface a number of receptors of Class II of the main histocompatibility complex (MHC) and T-cell receptors. Capturing the antigen and presenting it on the surface, LC leave the epidermis and migrate into regional lymph nodes.

Once the antigen has been introduced by LC mainly into CD4 + Th-1 lymphocytes, a cascade of cytokine release follows, produced basically by T-cell activation as well as other non-antigen specific T-cells and macrophages in this zone. Then, as a result, inflammation follows. The key cytokines are IL-1, IL-2, IL-3 and gamma-interferon. Inflammatory response reaches its peak at 72-nd hour and clinically manifests itself in the area of patch as localized eczema $[5,6]$.

Apart from the latex, which is a complete allergen, most dental materials are haptens, i.e. incomplete allergens. Their molecule must be linked to another one - more complex, such as a protein to cause allergic reactions. Haptens bind to protein or carbohydrate molecules of saliva, gingival fluid or blood and turn into unexpected allergenic permanent depots in the oral cavity $[7,8]$. Therefore we focused on studying the potential of dental materials to give rise to and maintain the allergic diseases urticaria and angioedema.

\section{Material}

The study included 110 patients of an average age 44,6 \pm 15,2 - 29 males (26.4\%) and 81 females (73.6\%); 50 patients with urticaria and angioedema from the Clinical center of Allergology in Alexandrovska Hospital, Sofia, Bulgaria and 60 control patients. Dental clinical examinations and survey about dental materials were recorded on a standardized form in FDM, MU Sofia.

The patients were divided into 3 groups:

- Patients with Angioedema (ANE) - 11 patients (10\% of the total number of patients included in the study) - 1-st working group

- Patients with Urticaria and ANE - 39 patients (35.5\% of the total number of patients included in the study) - 2-nd working group

- Control group - 60 patients (54,5\% of the total number of patients included in the study)

\section{Inclusion criteria:}

Patients aged over 18 with at least one dental restoration in the oral cavity (sealing, filling, crown, partial or full denture), a primary or secondary angioneurotic edema, hives. 
Exclusion criteria: patients under 18, patients with hereditary angioedema, patients with systemic medication (allergy therapy, ACE inhibitors), pregnancy

\section{Criteria for the control group:}

No common diseases and long-term drug therapy without proven allergy and autoimmune diseases. Clinical data was entered into Excel and subsequently exported to Statistical Package for Social Sciences (SPSS 21.0 for Windows) for statistical analysis. The prevalence proportion rates, mean values and standard deviations were calculated for the purpose of analysis. Statistical analysis was performed applying descriptive statistics and the independent sample Chi-square test, Fisher's Exact test in different groups. The level of statistical significance was fixed at $P=0.05$.

Initially all participants filled in a declaration of informed consent in which the upcoming diagnostic tests and the consent to use the results of scientific analyzes were explained in details. The names and types of available dental materials in the mouth of each patient were marked in specially designed questionnaire forms. The information was provided by a telephone conversation between the dental practitioners treating patients and the head of the study. For patchtest allergens were selected from various series of the company Chemotechnique diagnostics and from a series of ready dental products developed by the NCIPD Sofia, Bulgaria.

Two types of allergens were used on account of the study purposes - separate components and constituent parts of the dental materials and medicines, manufactured by the Swedish company (Chemotechnique diagnostics), and entire dental products - a series of 23 allergens, developed by National Center of infectious and parasitic diseases -NCIPD, Sofia, Bulgaria (scientific project № 28, contract № 22 of 2011). This series includes allergens of the following dental material groups: metal alloys - precious and non-precious, obturation materials - light curing and self adhesive polymers, plastics, sealers.

The survey and talks with the dental practitioners treating our participants helped us to identify the dental materials used for patient's treatment. Using the information received for each participant a patch was prepared with relevant allergens from entire products (series NCIPD) and individual substances, allergens from several series of Chemotechnique Diagnostics.

Patch test was done by classic method for diagnosing contact allergy. Hypoallergenic patches IQ Chambers ${ }^{\circledR}$ were used as well as allergens staying on patients back for 48 hours. The results were read a few hours after removing the patches and subsiding of reflected erythema. The reading of samples was performed according to the scale established by the International Contact Dermatitis Research Group:

$+\quad$ weak positive reaction - mild erythema, infiltration, possible availability of single papules

++ $\quad$ strong positive reaction - erythema, infiltration, papules, discrete vesicles;

+++ extreme positive reaction - coalescing vesicles, bullous or ulcerative reaction

IR - irritant reaction - disappears soon after removing the patch

? +- doubtful - faint macular, no infiltration, homogenous erythema

- $\quad$ negative reaction 
The sensitization to latex was determined by PRICK test and allergen product Alyostal (STALLERGEN) combined with positive and negative controls. The reactions were reported at the 20-th minute and the results of size (diameter) of wheal and flair over $3 \mathrm{~mm} / 3 \mathrm{~mm}$ were considered to be positive.

Aim: To study the sensitization to dental materials among patients with idiopathic form of urticaria and angioedema.

\section{Results and discussion}

The results of patchtest with dental materials, available in the oral cavity, showed that the highest proportion of patients with at least one sensitization regardless of its extent was reported in the group with ANE - 90.9\%, followed by the group with urticaria and ANE - $66.7 \%$ and lowest in the control group $30.0 \%$. The difference was statistically significant $(p<0.001)$, Table 1 .

Table 1: Sensitization to dental materials $(n=110)$

\begin{tabular}{|c|c|c|c|c|}
\hline \multirow{2}{*}{ Indicator } & \multicolumn{3}{|c|}{ Groups } & \multirow{2}{*}{ p-value } \\
\cline { 2 - 5 } & $\begin{array}{c}\text { ANE } \\
\mathbf{n}(\%)\end{array}$ & $\begin{array}{c}\text { Urticaria+ANE } \\
\mathbf{n}(\%)\end{array}$ & $\begin{array}{c}\text { Control group } \\
\mathbf{n}(\%)\end{array}$ & 18 \\
\hline Sensitization to dental materials & 10 & 26 & $<0.001$ \\
\hline
\end{tabular}

This fact should not be overlooked, since we have not found yet in the scientific literature a similar study concerning the relationship of idiopathic urticaria and ANE with possible sensitization to the materials used in dental treatment. Furthermore, it casts a different light on the medical diagnostic process and proves the need for a multidisciplinary approach to diagnosis and treatment.

The detailed examination of the results leads to very interesting conclusions. Table 2 presents the most commonly used dental materials in separate groups. 
Table 2: Comparative presentation of most commonly used dental materials regarding groups

\begin{tabular}{|c|c|c|c|c|}
\hline \multirow{2}{*}{ Dental materials } & \multicolumn{3}{|c|}{ Groups } & \multirow{2}{*}{$\begin{array}{c}\mathrm{p}- \\
\text { value }\end{array}$} \\
\hline & $\begin{array}{l}\text { ANE } \\
\text { n (\%) }\end{array}$ & $\begin{array}{c}\text { Urticaria+ANE } \\
\text { n ( } \%)\end{array}$ & $\begin{array}{c}\text { Control group } \\
\text { n (\%) }\end{array}$ & \\
\hline Non precious dental alloys & $8(72,7 \%)$ & $32(82,1 \%)$ & $37(61,7 \%)$ & 0,094 \\
\hline Methylmethacrilates & $9(81,8 \%)$ & $14(35,9 \%)$ & $6(10,0 \%)$ & $<0,001$ \\
\hline Ceramic & $3(27,3 \%)$ & $22(56,4 \%)$ & $31(51,7 \%)$ & 0,229 \\
\hline Amalgam & $2(18,2 \%)$ & $16(41,0 \%)$ & $22(36,7 \%)$ & 0,379 \\
\hline Phosphate cement & $8(72,7 \%)$ & $32(82,1 \%)$ & $36(60,0 \%)$ & 0,065 \\
\hline Other cements ( GIC,CHC) & $4(36,4 \%)$ & $25(64,1 \%)$ & $46(76,7 \%)$ & 0,024 \\
\hline Root canal sealers & $10(90,9 \%)$ & $33(84,6 \%)$ & $48(80,0 \%)$ & 0,630 \\
\hline $\begin{array}{l}\text { Self adhesive composite } \\
\text { materials }\end{array}$ & $6(54,5 \%)$ & $16(41,0 \%)$ & $22(36,7 \%)$ & 0,531 \\
\hline Light curing materials & $6(54,5 \%)$ & $30(76,9 \%)$ & $53(88,3 \%)$ & 0,024 \\
\hline
\end{tabular}

Judging by the available use of the sealers (90.9\%) the greatest number of endodontically treated teeth was registered in the first working group (ANE). Second position was occupied by the presence of plastic prostheses $(81.8 \%)$ and third by the available precious alloys $(72.7 \%)$. Other cements were used least frequently. The category "other cements" involves representatives of glass-ionomer cements (Ketac Cem, Aqua cem, GC Fuji plus caps., etc.) and calcium hydroxide cements (Calcimol LC, Hidropast, Calxid). The differences are statistically significant. In group 1, most rarely found restorations are those with amalgam (18.2\%) and ceramics (27.3\%).

Most often presence of the sealers (84.6\%) was found in the second working group - with urticaria and ANE, followed by the presence of phosphate cement (82.1\%) and base dental alloys (82.1\%). Plastic prostheses (35.9\%) and restorations with self-polymerized materials and amalgam (41.0\%) were recorded least frequently.

The lowest proportion of plastic restorations (10\%) and the highest regarding light-curing materials (88.3\%) and other cements (76.7\%) were established in control group. The differences are statistically significant.

This data is in accordance with unpublished results of our other research showing that the patients belonging to the group with ANE have the largest amount of extracted teeth. Dental restoration of such tooth-jaw abnormalities as the most optimal choice (time-money-quality) is done with plaque removable 
dentures, which in turn are based on methyl methacrylates. In control group the possibility of sensitization to methacrylates is at the expense of the contact with light curing materials.

The following Table 3 displays the most frequently inserted allergens in patchpatches with reported allergic reactions.

Table 3: Dental allergens

\begin{tabular}{|c|c|c|c|c|c|}
\hline Numb. & Allergen & Total & $\begin{array}{l}\text { Control } \\
\text { group }\end{array}$ & $\begin{array}{l}\text { Group 1- } \\
\text { ANE }\end{array}$ & $\begin{array}{c}\text { Group 2- } \\
\text { Urticaria } \\
\text { +ANE }\end{array}$ \\
\hline 1 & Abietic acid & $1(20,00 \%)$ & $0(0,00 \%)$ & $0(0,00 \%)$ & $1(100,00 \%$ \\
\hline 2 & Admira(voco) & $2(40,00 \%)$ & $0(0,00 \%)$ & $\begin{array}{l}1 \\
(100,00 \%)\end{array}$ & $\begin{array}{r}1 \\
(100,00 \%) \\
\end{array}$ \\
\hline 3 & Adseal & $1(12,50 \%)$ & $0(0,00 \%)$ & - & $1(25,00 \%)$ \\
\hline 4 & Amalgama & $6(33,33 \%)$ & $\begin{array}{r}3 \\
(25,00 \%)\end{array}$ & $\begin{array}{r}2 \\
(100,00 \%)\end{array}$ & $1(25,00 \%)$ \\
\hline 5 & Benzoylperoxide 1.0\% & $6(60,00 \%)$ & $\begin{array}{r}4 \\
(57,14 \%)\end{array}$ & $\begin{array}{r}1 \\
(100,00 \%)\end{array}$ & $1(50,00 \%)$ \\
\hline 6 & Bis-GMA & $3(30,00 \%)$ & $\begin{array}{r}2 \\
(33,33 \%) \\
\end{array}$ & - & $1(25,00 \%)$ \\
\hline 7 & Brealloy F400 & $2(28,57 \%)$ & $\begin{array}{l}1 \\
(25,00 \%)\end{array}$ & $0(0,00 \%)$ & $1(50,00 \%)$ \\
\hline 8 & $\begin{array}{l}\text { Chlorhexidine diacetate } \\
0.5 \% \text { aq }\end{array}$ & $1(3,57 \%)$ & $0(0,00 \%)$ & - & $1(20,00 \%)$ \\
\hline 9 & $\begin{array}{l}\text { Cobalt chloride } \\
\text { hexahydrate }\end{array}$ & $11(23,40 \%)$ & $0(0,00 \%)$ & $4(80,00 \%)$ & $7(31,82 \%)$ \\
\hline 10 & Colophonium & $2(25,00 \%)$ & $0(0,00 \%)$ & $\begin{array}{r}1 \\
(100,00 \%)\end{array}$ & $1(50,00 \%)$ \\
\hline 11 & $\begin{array}{l}\text { Copper() sulfate } \\
\text { pentahydrate }\end{array}$ & $3(37,50 \%)$ & $\begin{array}{r}2 \\
(33,33 \%) \\
\end{array}$ & - & $1(50,00 \%)$ \\
\hline 12 & Cortisomol & $2(22,22 \%)$ & $0(0,00 \%)$ & - & $2(50,00 \%)$ \\
\hline 13 & Cristaloy M & $0(0,00 \%)$ & $0(0,00 \%)$ & - & $0(0,00 \%)$ \\
\hline 14 & Cristaloy N & $3(42,86 \%)$ & $0(0,00 \%)$ & $2(66,67 \%)$ & $1(50,00 \%)$ \\
\hline 15 & Eugenol & $15(50,00 \%)$ & $\begin{array}{r}44 \\
(36,36 \%) \\
\end{array}$ & $6(75,00 \%)$ & $5(45,45 \%)$ \\
\hline 16 & Foredent ${ }^{\circledR}$ & $4(44,44 \%)$ & $\begin{array}{r}1 \\
(33,33 \%) \\
\end{array}$ & $2(66,67 \%)$ & $1(33,33 \%)$ \\
\hline 17 & Fragrance mix & $2(5,56 \%)$ & $0(0,00 \%)$ & - & $2(40,00 \%)$ \\
\hline 18 & Hydroabiethyl alcohol & $0(0,00 \%)$ & $0(0,00 \%)$ & - & - \\
\hline 19 & Indium $1.0 \%$ pet & $1(14,29 \%)$ & $0(0,00 \%)$ & $0(0,00 \%)$ & $1(25,00 \%)$ \\
\hline 20 & Mercury & $9(11,54 \%)$ & $3(6,39 \%)$ & $1(16,67 \%)$ & $5(20,00 \%)$ \\
\hline 21 & Methyl methacrylate & $3(33,33 \%)$ & $0(0,00 \%)$ & 2 & $1(33,33 \%$ \\
\hline
\end{tabular}




\begin{tabular}{|r|l|r|r|r|r|}
\hline & & & $(100,00 \%)$ & - \\
\hline 22 & $\begin{array}{l}\text { Methyldibromoglutaron } \\
\text { nitrile }\end{array}$ & $1(33,33 \%)$ & $0(0,00 \%)$ & $\begin{array}{r}1 \\
(100,00 \%)\end{array}$ \\
\hline 23 & metilchidroquinon & $0(0,00 \%)$ & $0(0,00 \%)$ & $0(0,00 \%)$ & $0(0,00 \%)$ \\
\hline 24 & $\begin{array}{l}\text { Nickel(\|)sulfate } \\
\text { hexahydrate }\end{array}$ & $22(29,73 \%)$ & $8(18,6 \%)$ & $1(20,00 \%)$ & $\begin{array}{r}13 \\
(50,00 \%)\end{array}$ \\
\hline 25 & Paladium & $0(0,00 \%)$ & $0(0,00 \%)$ & - & - \\
\hline 26 & PEG-400 & $0(0,00 \%) 1$ & $0(0,00 \%)$ & - & $0(0,00 \%)$ \\
\hline 27 & Potassium dichromate & $7(23,33 \%)$ & $0(0,00 \%)$ & $2(18,18 \%)$ & $5(29,41 \%)$ \\
\hline 28 & Propolis 10.0\% pet & $3(7,14 \%)$ & $0(0,00 \%)$ & $0(0,00 \%)$ & $3(20,00 \%)$ \\
\hline 29 & textile dye & $3(33,33 \%)$ & $0(0,00 \%)$ & $0(0,00 \%)$ & $3(60,00 \%)$ \\
\hline 30 & Titanium 10.0\% pet & $2(28,58 \%)$ & $0(0,00 \%)$ & - & $2(66,67 \%)$ \\
\hline 31 & Transbond XT & $1(50,00 \%)$ & 1 & - & - \\
\hline 32 & Triclosan 2.0\% pet & $6(35,29 \%)$ & $(50,00 \%)$ & 2 & $3(75,00 \%)$ \\
\hline 33 & UDMA & $5(35,71 \%)$ & $(16,67 \%)$ & $(100,00 \%)$ & $1(25,00 \%)$ \\
\hline 34 & $\begin{array}{l}\text { Zirconium (IV)chloride } \\
\text { 1.0\% pet }\end{array}$ & $1(11,1 \%)$ & $1(50,00 \%)$ & 1 \\
\hline 35 & Argelloy NP special & $0(0,00 \%)$ & $0(0,00 \%)$ & - & $0(0,00 \%)$ \\
\hline 36 & Endometason & $2(22,22 \%)$ & $0(0,00 \%)$ & $1(50,00 \%)$ & $2(25,00 \%)$ \\
\hline
\end{tabular}

It is obvious that the group of metals and metal ions is the most numerous.

It turns out that metal alloy Cristaloy $\mathrm{N}$, copper and mercury amalgam have the highest sensitizing potential among the research participants while nickel, titanium and metal alloy Brealloy $F 400$ have marked a little lower sensitizing potential. Metal alloy Argelloy NP Special and Paladium did not give any reaction to sensitization. They were tested only in control group without having given a positive response. What is the significance of such results? They partially confirm previous studies in this field, related to the allergenic potential of metal alloys containing nickel, and the effects of amalgam $[9,10,11]$. On the other hand it was found that patients respond differently to testing with allergen from entire product. For example, sensitivity to alloy Cristaloy $\mathrm{N}$ is $86 \%$, which is the highest, but to its main component nickel it drops to $29.73 \%$. On the contrary sensitization to copper as a component of the amalgam composition and some noble dental alloys is $37.5 \%$, while to the amalgam itself is $33.3 \%$. These findings confirm the need for testing using both types of allergens - from entire dental products and individual components, since the finished product is placed into the patient's mouth.

Considering the demonstrated sensitization to metals and metal alloys groups it can be found that the participants of the first group (ANE) have shown $100 \%$ sensitization to amalgam (80\%), cobalt (66.6\%) and Cristalloy $\mathrm{N}$ alloy, Figure 1. 
Fig.1 Sensitization to metal ions and alloys by groups

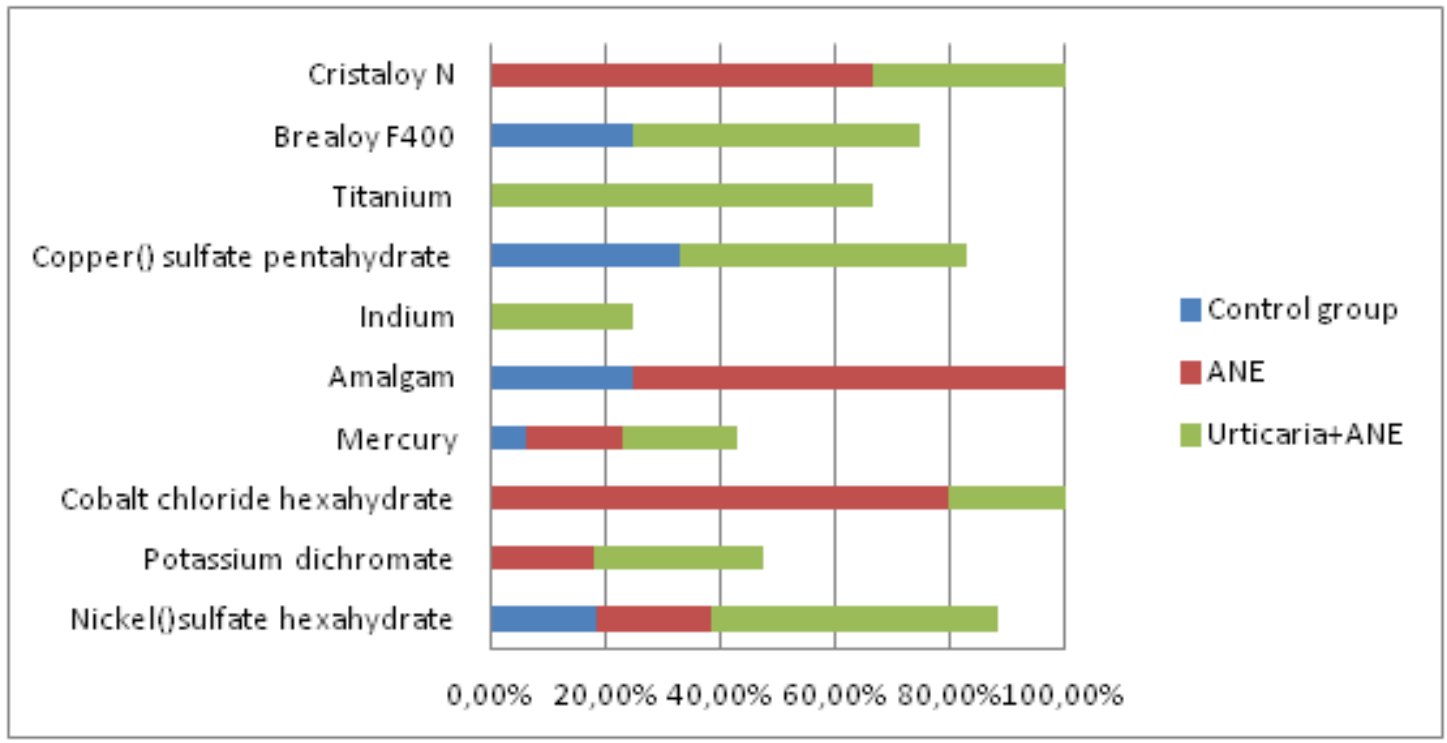

The participants of the second group turned out to have superimposed sensitization to titanium (66.67\%), Brealoy and Cristalloy $\mathrm{N}$ and nickel (50\%).

In control group most numerous reactions are registered to copper (33.3\%) and Brealoy alloy (25\%). Brealloy F400 (Bredent) is a cobalt-chrome-molybdenum alloy. Such alloys have the highest mechanical properties among other metal alloys [13]. The presence of molybdenum gives the fine structure of the crystals, which makes the alloy much more corrosion resistant. Although this and all other alloys have good physical and chemical properties, we should bear in mind that they may lead to sensitization and allergic reaction even in non-allergic patients as is the case here.

\section{Root canal Sealers}

The purpose of using sealers is to fill hermetically the root canal after endodontic treatment until the apical constriction. Such materials are a combination of drugs having an antiseptic, anti-inflammatory effect. Sealers remain permanently in canal system of endodontically treated tooth and depending on the technique of processing and filling the root canal (overfilling) can remain in constant contact with periodontal tissues. This contact leads to different types of immune interactions - firstly, sensitization and secondly to allergic inflammation.

It becomes clear from the results that eugenol has highest sensitizing potential of tested substances total for the three groups $-50 \%$. It is followed by Foredent (44.44\%), which is shown in table 3.

Eugenol is the main plasticizer in zinc-oxide sealers. It possesses antiseptic and anti-inflammatory properties [12]. It is derived mainly from cloves, but also occurs in camphor and cinnamon. Eugenol may be present in impression materials, periodontal dressings and means for temporary filling. It is one of the most commonly used scents in antiperspirants. Sensitization to eugenol can occur not only due to dental materials and cosmetics, but also food. It is added in chewing gums and chocolates.

Foredent ${ }^{\circ}$ - is powder materials and liquid, belonging to formalin - resorcinum sealers. They are plasticized with two fluids mixed in equal parts immediately before the preparation of the filling paste. One 
fluid is the solution of formalin and the other of resorcinol. Dust contains formaldehyde, barium sulfate and zinc oxide. It is used for preparing a paste for the treatment of pulpitis and periodontitis. Ex tempore is prepared.

The major allergen in this type of pastes is formaldehyde $(F)$. There are cases of contact skin urticaria induced by $F$ contained in the sealer paste as well as those of anaphylactic reactions to $F$ in the composition of endodontic sealer - four cases of anaphylactic shock, and three of generalized urticaria with fixing F- specific IgE-antibodies. According to Tas et al. (2002) [13] 28 cases of allergic immediate reactions to $\mathrm{F}$ contained in canal fillings have been described in the literature. In their study, the authors described a case of a patient who developed acute urticaria twice following treatment with two different filling materials. His allergy test indicated the presence of F-specific IgE-antibodies and patchtests were positive for F-containing dental material. In a more recent study of Kijima et al. (2007) [14] 2 more cases were depicted of generalized urticaria after treatment with endodontic sealer where it was diagnosed type I allergic reaction to formaldehyde. The authors summarized the literature data and the characteristics of this type of allergic reactions - similar to anaphylactic symptoms and tendency symptoms to manifest a few hours later than in common cases of anaphylaxis. They recommended carrying out a test for the presence of F-specific IgE-antibodies in patients at risk.

The distribution of sensitization to the sealers into groups shows that in group 1 sensitization to colophonium is the highest, followed by eugenol, foredent and endomethasone.

Eugenol and Foredent are substances that showed sensitization in all three groups - figure 2.

Fig.2 Sensitization to root canal filling materials by groups

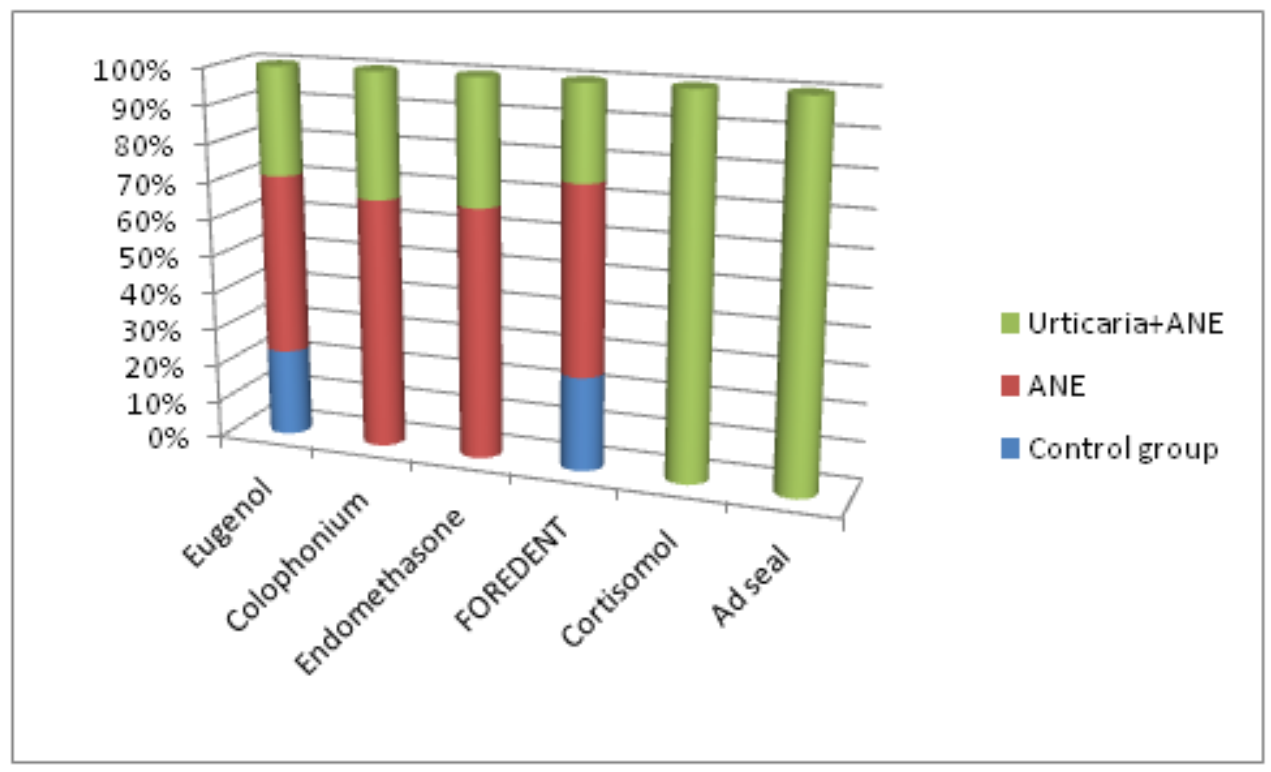

Colophonium is a term used for general hardened form of resins from pine, cedar, spruce, fir and juniper. It is classified as one of the top 10 allergens in many countries and is often a cause for professional contact dermatitis. Colophonium is commonly found in the composition of dental materials (sealers) and topical medications. It is widely used flavor and flavor enhancer which can be found in chewing gums, 
dental floss, impression materials and periodontal dressings [15]. The clinical manifestation of contact hypersensitivity can occur as painful ulcerations, burning and contact stomatitis [3].

In second group the wider range of used sealers is noticeable and respectively - higher sensitization to them is impressive, as well - Cortisomol (50\%), Colophonium (50\%), Eugenol (45\%).

Cortisomol ${ }^{\circledR}$. It contains Delta hydrocortisone $1 \mathrm{~g}$, Trioxymethilene $2.5 \mathrm{~g}$, Di-iodothymol $24 \mathrm{~g}$, and Minium $11 \mathrm{~g}$.

Endomethasone ${ }^{\circledR}$. It contains Dexamethasone $10 \mathrm{mg}$, Eugenol $91 \mathrm{ml}$, Hydrocortisone acetate $1 \mathrm{~g}$, Paraformaldehyde $2.2 \mathrm{~g}$, Thymol lodine $25 \mathrm{~g}$, etc. Oddly enough is the fact that even if there is corticosteroid in both pastes - Delta hydrocortisone and Dexamethasone we report a positive skin reaction [16].

In control group sensitization is found basically to Foredent (36.36\%) and Eugenol (33.33\%).

\section{Composites}

Composite materials are synthetically produced products composed of organic and inorganic ingredients. The most frequently used organic ingredient is BIS - GMA. Other dimethacrylate oligomers - TEGDMA, EGDMA are added [12] in order to reduce the viscosity of this ingredient. Frequently, entirely or partly the organic component of the composite materials contains UDMA. The inorganic component is called filler and it may be quartz, silicon, lithium aluminum silicate, ceramic particles, barium-aluminum-borosilicate. To obtain a strong covalent bond between the organic matrix and filler particles, the latter are silanized. Over time, this relationship can degenerate due to imbibition of saliva from the composite (Anastasov, 2013). There are different views on the sensitization to methacrylates. According to the authors $[17,18]$ it is not only high, but also quite frequent. Ekstrand $\mathrm{J}$ et al(1998) [19] say that the quantities of the acrylic substances released are normally too small to cause systemic reactions, therefore the mucosal lesions are prevalent.

Composites are used for fillings, fissure sealing and cementing. Depending on their function various components are added to their basic composition in order to ensure longer processing time, opportunity for light-curing and others. The combinations of substances are practically thousands in the final product. For our study purposes we selected some components of composites and two final light curing products due to their frequency - Admira, brackets adhesive - Transbond TM XT Light Cure Adhesive - 3M.

Highest sensitization was found to Benzoil peroxide total in all three groups - table 3 . BP initiates polymerization in conventional plastics and it is also present in some filling materials. Benzoil peroxide is widely used initiator, vulcanizer and crosslinking agent in the polymerization process (primarily in curing of unsaturated polyester resins, production of polystyrene and similar resins, styrene polymers and other resins). Lynde at al (2014) [20] performed a retrospective review of the patchtesting outcomes in patients with a diagnosis of burning mouth syndrome. Benzoyl peroxide (1\%) is among the most common allergens. In present study, sensitization to BP turns out to be twice greater than that to Bis- GMA, MM and UDMA (urethane dimetacrilat). The positive reaction to Transbond $\mathrm{TM} X \mathrm{XT}$ Light Cure - brackets adhesive is also worth mentioning, although it is found only in control group. It indicates the presence of specific orthodontic treatment and suggests that dental materials for this treatment - nickel titanium arcs, bands and brackets should also be pre-tested for individual biocompatibility [21].

Figure 3 shows the distribution of reported positive reactions to composites in separate groups. 
Fig.3 Sensitization to methacrylic derivatives and components by groups

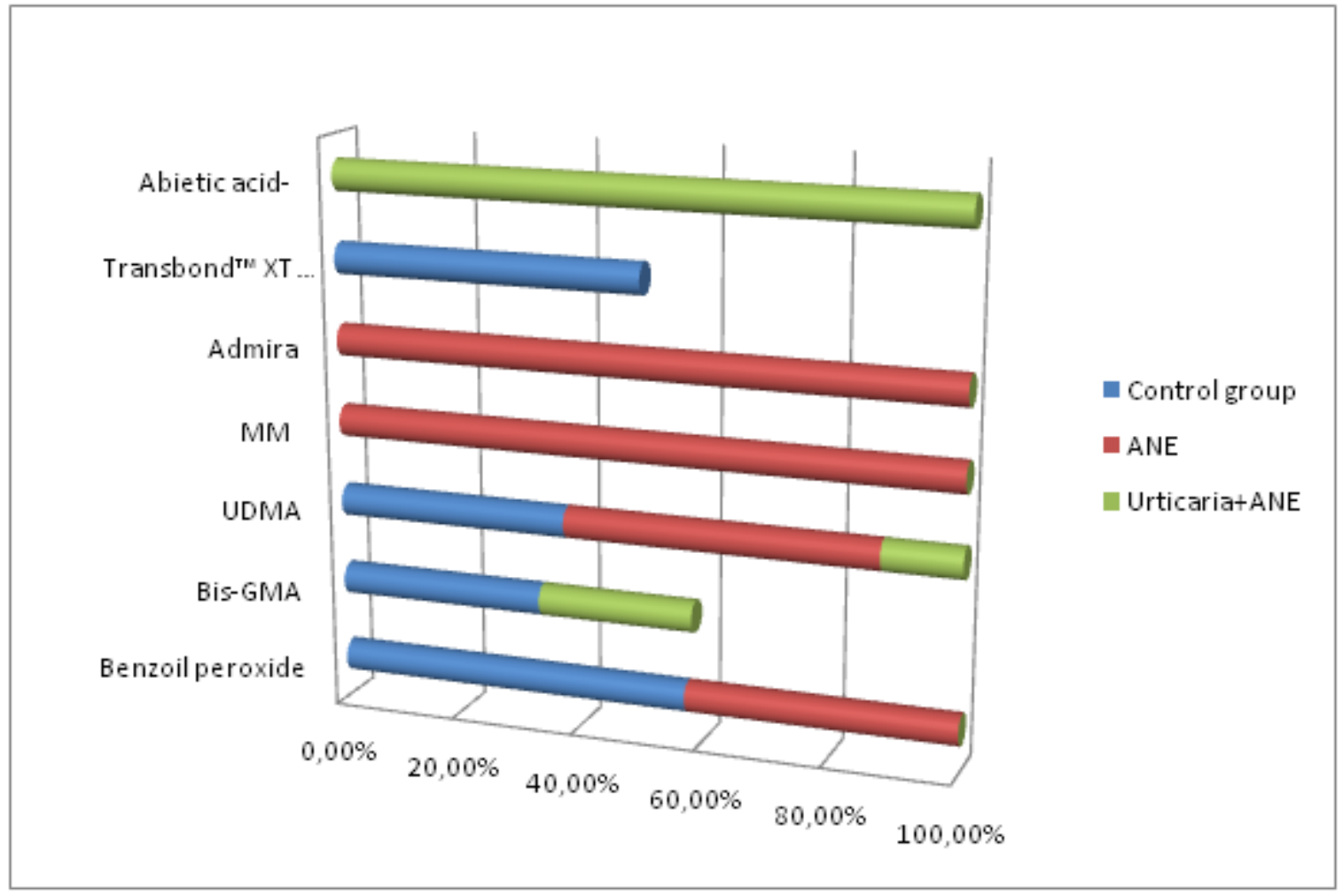

Sensitization to MM, BP, composite Admira in group 1 was found to be the highest. Sensitization to BIS GMA was not reported.

In group 2 it was recorded sensitization to Admira and Abietic acid, which is a substance that is a component of some dental impression materials, composites, sealants, adhesives.

Admira (Voco) - Light-curing Ormocer ${ }^{\circledR}$ is organically modified ceramic, the composition of which BISGMA and UDMA enter. The material is of optimized quality and has much less compressibility during light polymerization. This prevents the formation of micro-chink between hard tooth tissue and obturation.

This fact proves once again that despite perfect mechanical and physical properties of obturation material sensitization is not beyond the bounds of possibility.

\section{Oral hygiene means}

Oral hygiene means are products that are used to carry out both personal and professional oral hygiene. These include toothpaste, mouthwash, dental floss and substances improving their taste and smell. Figure 4 indicates clearly that the highest sensitization has been recorded to triclosan, propolis and fragrance mix among three groups. 
Fig.4 Sensitization to oral hygiene disinfectants by groups

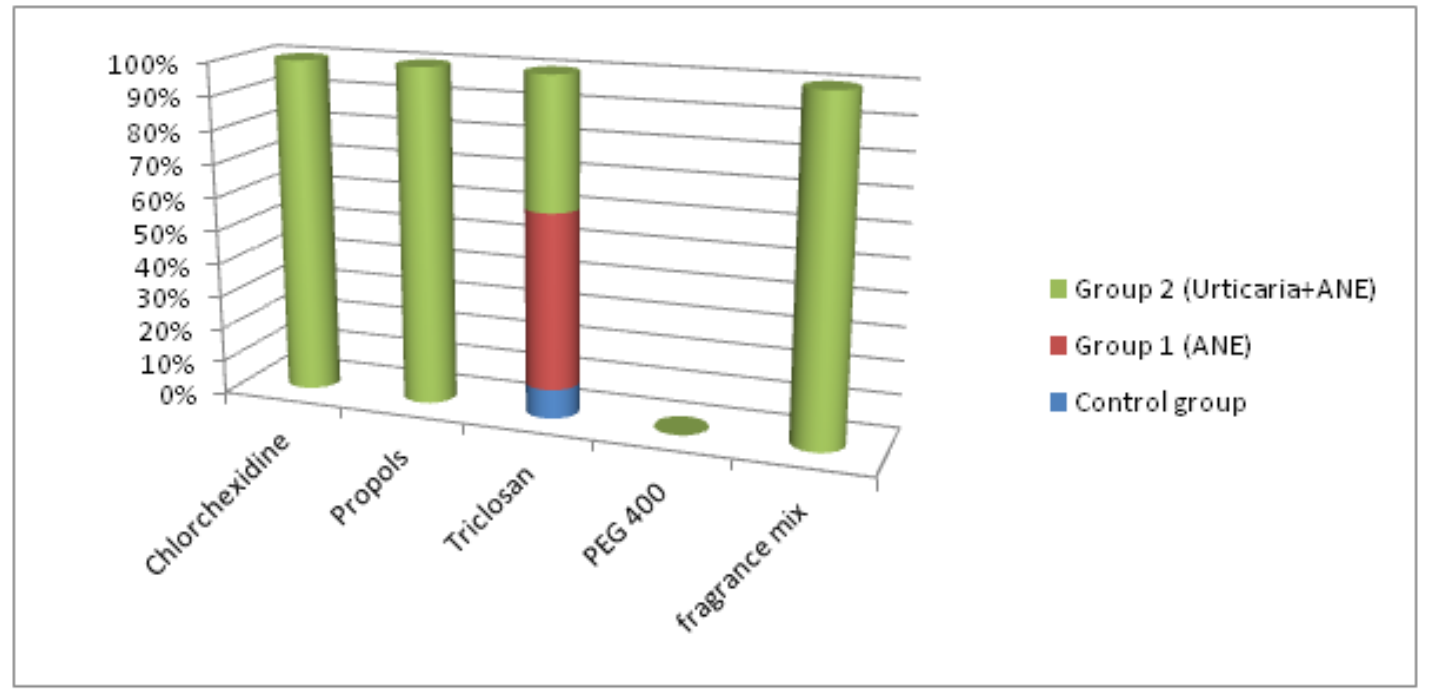

Triclosan is used as an antimicrobial agent in the composition of personal hygiene products - toothpaste, mouthwash and antibacterial soaps, as well as in consumer products - detergents, plastics and others.

Propolis is a natural bee product. It is a part of the composition of many toothpastes, mouthwashes and periodontal dressings. It has regenerating action on epithelial cells. A serious drawback is its sensitizing potential [22].

Fragrance was declared as the Contact Allergen of the Year for 2007 by the American Contact Dermatitis Society [23].

There are more than 5000 different fragrances that are in use today. A huge number of fragrances can be used in any product. Fortunately only a small number of fragrances are actually common sensitizers and cause allergy in sensitive individuals.

Fragrance mix is a mixture of 8 individual fragrances (Cinnamic alcohol, Cinnamic aldehyde, Eugenol, Isoeugenol, Geraniol, Oak moss absolute, Hydroxycitronellal, Alpha amyl cinnamic alcohol) that are used to screen fragrance allergy. The 8 listed above are the most common allergy-causing fragrances being used in many products for their fragrant and flavouring properties.

Sensitization to triclosan has been found in all three groups with the highest frequency in the first group with ANE. It strikes that other allergens have shown response only in patients of group 2.

\section{Latex allergy}

Latex is the rubber tree extract, which contains over 260 proteins. Sources of latex proteins in dental office are most often gloves, carpule rubber seals, local anesthetic, saliva ejector tubes, polishers, orthodontic bands, endodontic stops and rubber-dam. It is common sensitization to latex allergen to be more often 
professional, but it can also be detected among people with food allergies [24]. There is also cross-type sensitization which is due to common antigenic epitopes with fruits such as bananas, kiwi, avocado, spinach [25]. The results are presented in the table below.

Table 4. Comparative presentation of the sensitization results to latex protein in groups $(n=110)$

\begin{tabular}{|l|c|c|c|}
\hline \multirow{2}{*}{ Groups } & \multicolumn{2}{|c|}{ Allergy t latex protein } & \multirow{2}{*}{ p-value } \\
\cline { 2 - 3 } & Not establish & Establish & \\
\hline ANE & $9(81,8 \%)$ & $2(18,2 \%)$ & \multirow{2}{*}{0,864} \\
\hline Urticaria+ANE & $31(79,5 \%)$ & $8(20,5 \%)$ & \\
\hline Control Group & $44(73,3 \%)$ & $16(26,7 \%)$ & \\
\hline
\end{tabular}

The highest proportion of sensitization to latex protein has been recorded in patients of the control group $26.7 \%$, followed by the second working group with $20.5 \%$ and lowest reported proportion in the first working group - $18.2 \%$. No statistically significant difference has been found between the three groups. However, we can claim that there is no correlation between the latex sensitization and manifestation of urticaria and angioedema, as in the control group it is the highest.

\section{Conclusion}

Current trends in dental diagnosis and patients' treatment are subject to the demand of individual and minimally invasive approach. In this context the medical algorithm in patients with allergic disease is supposed to be referred first to consideration of biocompatibility of dental materials since their impact on general health status has not been studied fully yet. Our study proves statistically significant higher sensitization to dental materials in the oral cavity among patients with idiopathic urticaria and angioedema. Our results exclude the potential impact of latex in such forms of urticaria and angioedema but make us rethink the selection of dental medications and materials that will be used for the treatment of such patients. Regarding patchtesting we recommend using two types of allergens - of individual components and of ready dental products, due to the way they are inserted in the oral cavity and stay there for a long time in contact with the oral mucosa and ecosystem. This way of testing most completely encompasses the possible hidden effects and is in accordance with the understanding of diagnostic products preparation from minor and major allergens.

The research has been done with regard to the funded project № 9-C / 2015 by the Board of Medical Science of MU - Sofia.

No potential conflict of interest has been reported as regards the project implementation and results publication by the members of the research team. 


\section{References}

1. Mansi M, Zanichelli A, Coerezza A, Suffritti C, Wu MA, Vacchini R, et al. Presentation, diagnosis and treatment of angioedema without wheals: a retrospective analysis of a cohort of 1058 patients. J Intern Med. 2015 May; 277(5):585-93p.

2. Marx J, Hockberger R, Walls R. Rosen's Emergency Medicine. 7th ed. Mosby; 2009. Urticaria and angioedema.

3. Dencheva M, Balcheva M, et al. Dental clinical allergology. „Za bukvite”, 2014.

4. Stoeva I. Practical handbook of dental clinical allergology, MU Plovdiv, Faculty of dental medicine, 2011.

5. Petrunov B, Dimitrov V, Kisselova A. Allergology and oral medicine: Principles and practice, I. Sapundjiev LtD, 2013.

6. Kisselova A, Petrunov B. Edit. Biocompability in oral medicine. From theory to practice. Sofia. Medinform, 2016, $384 \mathrm{p}$.

7. Petrunov B, Dimitrov V, Kisselova A. Clinical immunology. Clinical allergology. Dental clinical allergology, Med.publ. „Arso”. 276 p.

8. Ivanova I. Intraoral contact hypersensitivity to prosthodontic materials, Dissertation, 2008, $173 \mathrm{p}$.

9. Grawkrodger DJ. Investigation of reactions to dental materials. Br. J.Dermatol, 2005;153:479-485.

10. Syeed $\mathrm{M}$, et al. Allergic reactions to dental materials - a systematic review. J of Clin and Diagnostic research, 2015;9(10):4-9.

11. Panov V, Markova M, Krasteva A, Kisselova A, Lyapina M. Evaluation of blood mercury levels in dental students and dental professionals. Oral Diseases, 2016;22(Suppl. 2):14-41.

12. Anastasov., I., Dental material science. 2013. Printed by Sofia smile centre. 316 p.

13. Tas E, Pletscher M, Bircher AJ. IgE-mediated urticaria from formaldehyde in a dental root canal compound. J Investig Allergol Clin Immunol. 2002;12(2):130-133.

14. Kijima A, Nishino $\mathrm{H}$, Umeda J, et al. Type 1 allergy to formaldehyde in root canal sealant after dental treatment: two case reports and review of the literature. Arerugi. 2007;56(11):1397-1402p.

15. http://www.chemotechnique.se

16. Forman $\mathrm{GH}$, Ord RA. Allergic endodontic angio-oedema in response to periapical endomethasone. Br Dent J. 1986 24160(10):348-350.

17. Lyapina M, Dencheva M, Krasteva A, Tzekova M, Deliverska M, Kisselova A, Staikova J. Health risk assessment in exposure to methacrylic monomers in dental practice. Journal of Scientific Research \& Reports, 2014;3(22):2848-2863.

18. Chonin A, Stoeva I. Clinical manifestations of intraoral contact hypersensitivity among dental patients with methacrylate allergy. J IMAB, 2016;22(4):1411-1413.

19. Ekstrand J, Björkman L, Liu Y, Sköldqvist B, Björkner B. New dental materials a health risk for dental staff. Acrylates can cause contact allergy and other problems. Lakartidningen. 1998;95(25):29462949.

20. Lynde CB, Grushka M, Walsh SR. Burning mouth syndrome: patch test results from a large case series. J Cutan Med Surg, 2014;18(3):174- 9.

21. Kisselova A, Stoeva I, Krasteva A. Allergy in orthodontics. Problemi na stomatologiata, 2005;XXXII:75-79.

22. Kisselova A, Usunov Tz, Stoeva I. Prpolis induced contact allergy. Problemi na dentalnata medizina, 2006;XXXII:59-63. 
23. http://www.contactderm.org

24. Balcheva M. Orofacial manifestations of some allergic diseases, MU Varna, 2016, $152 \mathrm{p}$.

25. Işık S, Arıkan-Ayyıldız Z, Çağlayan-Sözmen Ş, et all. Cross-reactivity syndromes: presentation of two cases and review of the literature. The Turkish Journal of Pediatrics, 2014;56:291-294.

\section{Corresponding author:}

Assoc.prof. dr Maria Dencheva, PhD

St.Georgi Sofiiski Blvd. № 1,

MU Sofia, Faculty of dental medicine,

Department of imaging and oral diagnostic

Sofia 1431, Bulgaria

0359889317316

dr.maria.dencheva@gmail.com 